\title{
Implications of Generic Skills on Innovative Behavior Towards Opportunity Recognition in Youth
}

\author{
Rohana Ngah ${ }^{1}$, Rahimah Sarmidy ${ }^{1} \&$ Nurul Hafez Abd Halil ${ }^{1}$ \\ 1 Malaysian Academy of SME and Entrepreneurship Development, Universiti Teknologi MARA, Shah Alam, \\ Malaysia \\ Correspondence: Rohana Ngah, Malaysian Academy of SME and Entrepreneurship Development, Universiti \\ Teknologi MARA, 44000 Shah Alam, Malaysia. E-mail: rohanangah@uitm.edu.my
}

Received: December 11, 2019

Accepted: January 18, 2020

Online Published: March 5, 2020

doi:10.5430/rwe.v11n1p123

URL: https://doi.org/10.5430/rwe.v11n1p123

\begin{abstract}
The high competition in the employment market and high unemployment rate prompted the government to encourage entrepreneurship as a career option for students further. Many entrepreneurship programs and courses have been developed and offered in higher learning institutions to encourage innovative behavior and the ability to recognize opportunities, especially in the emerging digitization world and the high unemployment rate in Malaysia. Generic skills such as creativity, proactiveness, risk-propensity, leadership, motivation, and self-efficacy are said to be essential determinants for innovative behavior. This paper aims to investigate the impact of generic skills on innovative behavior and opportunity recognition empirically. The online survey was conducted on 225 students who took a technology entrepreneurship course at a Malaysian university. Data were then analyzed using Partial Least Square software. Only creativity and proactive have a strong influence on innovative behavior and opportunity recognition. The mixed results implied that more efforts to carry out to enhance further the innovative behavior of students in preparing them to real-world challenges. It is timely to readdress how to improve further and strengthen the generic skills of students. Recommendation and suggestions are presented.
\end{abstract}

Keywords: generics skills, innovative behavior, opportunity recognition, youth, technology entrepreneurship, Malaysia

\section{Introduction}

Youth constitutes more than $40 \%$ of Malaysia's population, with a literacy rate of 98.5\%. (Tey, Lai \& Ismail, 2019). In supporting the government's goal to be a high-income nation through the high-tech economy, youth plays a significant role as an economic catalyst. As Malaysia's unemployment rate hits $10.2 \%$, youth need to be innovative and should be able to recognize the opportunity to compete with others. The challenges of the future - globalization, climate, technological, and demographic change - require a different response from the education system. Students who are the future generation need to be equipped with strong fundamental skills and specialist technical knowledge, but with the attitudes and broader skills to generate radical new solutions and adapt to the rapidly changing world, especially in response to the Industrial Revolution 4.0. Malaysia is committed to improvising its innovation level by providing world-class infrastructures and innovation activities from schools to universities. The literacy level of Malaysian youth is high, and the high quality of vocational education has provided a better opportunity for youth to be creative and innovative. In universities, youth have been exposed to innovative skills through informal and formal activities. Youth hold the key to the future innovation of the nation as they make up almost 50 percent of the global workforce and create new job-creation strategies (Lovell, 2017). Nurturing youth to be innovative through their generic skills is crucial for the nation's future economic growth. Innovative workers are essential for a progressive nation where creativity and innovation have become a new asset and resource. Despite numerous programs and initiatives to promote innovative behavior among youth, the contribution of youth in the area is still vague. To date, there are very few studies relating to the topics that have been carried out. Opportunity recognition is a first step in exploring entrepreneurship. Opportunity recognition is seldom discussed and promoted, especially in the education area. It is crucial not only to nurture generic skills towards innovative behavior development but also foster opportunity recognition skills. The main question is what factors influence their innovative behavior from the perspective of generic skills that leads to opportunity recognition. Therefore, this paper attempt to explore further on 
this aspect. This research paper contributes to the comprehending of innovative behavior in the context of youth in Malaysia.

\subsection{Research Background}

This section discussed the relationship of variables under study, namely, opportunity recognition, generic skills, and innovative behavior. Many initiatives are done in universities to provide generic skills to build strong characteristics of students. By being able to recognize opportunities, students would be ready to embark on their career paths. Previous studies relating to opportunity recognition focus on working adults (Crebert, Patrick \& Cragnolini, 2004) and small and medium enterprises (Sambasivam, Abdul, and Yusop, 2009). Few studies on generic skills have been carried out in Malaysian youth but focus more on the perception of students (Devadason, Subramaniam and Daniel, 2010) and implementation of generic skills in the curriculum (Yassin et al., 2008). Malaysia's government has emphasized the importance of generic skills in increasing employability in Malaysia (Ministry of Higher Education, 2015). However, very few studies explore opportunity recognition, generic skills, and innovative behavior towards entrepreneurship, which is very important to reduce unemployment issues in Malaysia.

\subsection{Opportunity Recognition}

The exploitation of opportunity especially would help youth to create their job and be independent. Opportunity recognition is one of the essential elements in entrepreneurship, especially in tackling the unemployment issue. According to Kuckertz et al. (2017), even though the importance of opportunity recognition and opportunity exploitation are known; however, it is not well explored, thus open up to more debates. Opportunity recognition refers to the alertness of potential business opportunities. Opportunity can be recognized through activities like scanning the environment and communicating with customers and users. Heinonen et al. (2011) posit that innovative behavior has a secure connection to business opportunity recognition. In recognizing a business opportunity, Dyer et al. (2008) suggest that individuals must be proactive, especially in searching and gathering information. Kim et al. (2018) found that innovative behavior has a strong influence on opportunity recognition as well as generic skills is important to help students to recognize opportunities (Wasdani and Manimala, 2015).

\subsection{Innovative Behavior}

Innovative behavior refers to the introduction and application of new ideas, products, processes, and procedures to a person's work role, work unit, or organization (Yuan \& Marquardt, 2015; Riaz, Yu \& Hussain, 2018). The innovative behavior can be carried out either by an individual or members of a group in the organization. Rapid technological and social changes in society contribute to innovative behavior, especially among undergraduates (UNCTAD, 2019). Innovative behavior among undergraduates is crucial for institutional growth and survival. Innovative behavior was, for example, described by De Jong, Jeroen \& Den Hartog (2005) as self-initiated innovative behavior, which is a process in which new ideas are generated, created, developed, applied, promoted, realized, and modified for benefits. As students had attended a few entrepreneurship classes and entrepreneurship programs on campuses, they were expected to acquire few generic skills. The important puzzle is whether students can capitalize and maximize their generic skills towards opportunity recognition with the influence of innovative behavior. Many activities carried out in encouraging innovative behavior.

\subsection{Generic Skills Relating to Innovative Behavior}

According to Chell and Athayde (2009), five generic skills contributed to innovative behavior, namely, creativity, self-efficacy, energy, risk propensity, and leadership. Creativity comprises of imagination, connecting ideas, tackling and solving problems, curiosity (Swaroop \& Dixit, 2017). Self-efficacy has been frequently identified to be an essential element for entrepreneurship intention (Ngah \& Osman, 2017) and innovative behavior (Hsiao et al. 2010). Bandura (1979) defined self-efficacy as "people's beliefs about their capabilities to produce designated levels of performance that exercise influence over events that affect their lives." Individuals with a high sense of self-efficacy are regarded as more likely to have better performance and commitment, especially during a difficult moment (Weaver, 2016). Energy refers to enthusiasm, motivation, persistence, and commitment (Chell \& Athayde, 2010). Even though risk-propensity is widely researched in entrepreneurship setting, however, there is a gap of research relating to risk propensity to entrepreneurial intention and innovative behavior (Antoncic et al. 2018). Leadership refers to individuals who can direct, motivate, and lead themselves towards achieving desired behavior (Carmelli et al. 2006). Kong and $\mathrm{Li}$ (2017) found in their study that proactive personality has a substantial impact on innovative behavior. The individual that possesses a proactive personality tends to take the initiative to improve the current situation or create a new situation rather than passively waiting for a change ( $\mathrm{Li}$ et al. 2017).

From the literature review, two hypotheses have been derived: 
H1: Generic skills have a significant relationship with innovative behavior

H2: Innovative behavior has a significant relationship to opportunity recognition

\section{Method}

This study focused on undergraduate students who attended technology entrepreneurship classes. This course is only offered to students of the Science \& Technology Cluster, and most of them were in their final year. In the course, students were exposed to the concept of creativity and innovation. Several activities were carried out to encourage innovative behavior among students, especially to propose innovative products. A quantitative method of survey research was deployed. Survey research deemed suitable as the aim of the study is to explain the features of a large group. Data were collected using a questionnaire that used a five-point Likert scale response format. A sample random sampling technique was employed because of the relevance of its nature to this study. The online survey was conducted as it is cheaper, faster, and suit to the nature of respondents. The total population of students in this program was almost 2000. A total of 246 responses were returned, indicated a 12.3 percent response rate. However, only 225 responses were completed and usable. All item measurements were adopted from Chell and Athayde (2009) in exploring young people's innovative behavior in the United Kingdom.

\section{Results}

The majority of respondents were female $(60 \%)$, and $40 \%$ are male. Almost $90 \%$ were in the age range of $22-25$ years old. Students from the Faculty of Applied Science represented the majority of respondents (37\%), followed by the Faculty of Electrical Engineering (23\%) and Faculty of Survey and Architecture (13\%). Most of the respondents had attended innovation or invention events between 1-3 times in the last three years $(58.9 \%)$. About $37 \%$ of respondents had taken part in innovation and invention competitions for the last three years, and $63 \%$ had never participated in any innovation and invention competition.

A multivariate analysis technique of Structural Equation Modeling was used through Partial Least Square software. All data collected were analyzed using SPSS for descriptive analysis and Partial Least Square for multivariate analysis. SmartPLS Version 3 was used to assess and estimate the parameters in the outer and inner models. PLS provides many advantages with distribution requirements, type of variables, sample size, and the Complexity of the model to be tested. This study utilized PLS path modeling with a path-weighting scheme for the inside approximation (Wetzels et al., 2009). The nonparametric bootstrapping approximation was applied with 500 resamplings to obtain the standard errors of the estimates (Wetzels et al., 2009). A PLS path model consists of two elements, namely, the measurement model and the structural model.

\subsection{Measurement Model Assessment}

The measurement model represents the relationships between the constructs and the variables. In measurement model assessment, convergent validity and discriminant analysis are tested to evaluate the reliability and validity of the construct measures. Once the validity and analysis meet the requirements of the measurement model, the structural model will be explored.

\subsubsection{Convergent Validity}

Factor loadings, composite reliability, and average variance extracted were used to assess convergent validity. The loadings for all items exceeded the recommended value of 0.5 (Hair et al., 2010). Table 2 represents the convergent validity and discriminant analysis. Composite reliability values that depict the degree to which the construct indicators indicate the latent construct ranged from 0.759 to 0.868 , which exceeded the recommended value of 0.7 (Hair et al., 2010). The average variance extracted, which reflects the overall amount of variance in the indicators accounted for by the latent construct, were in the range of 0.514 and 0.642 , which exceeded the recommended value of 0.5 (Hair et al., 2010). Therefore, the measures of all the variables/constructs have acceptable levels of convergent validity.

\subsubsection{Discriminant Analysis}

The purpose of discriminant validity is to detect any multicollinearity issues among variables (Hair et al. 2010). The discriminant analysis can be done by comparing the squared correlations between constructs and the average variance extracted for a construct (Fornell and Larcker, 1981). As shown in Table 2, the squared correlations for each construct are less than the average variance extracted by the indicators measuring that construct indicating adequate discriminant validity. In total, the measurement model demonstrated adequate convergent validity and discriminant validity. 
Table 2. Convergent validity and discriminant analysis result

\begin{tabular}{lllllllllll}
\hline & CR & AVE & 1 & 2 & 3 & 4 & 5 & 6 & 7 & 8 \\
\hline Creativity & 0.870 & 0.771 & 0.878 & & & & & & & \\
Innovative Behavior & 0.827 & 0.545 & 0.482 & 0.738 & & & & & & \\
Leadership & 0.843 & 0.642 & 0.391 & 0.355 & 0.801 & & & & & \\
Motivation & 0.848 & 0.736 & 0.418 & 0.436 & 0.327 & 0.858 & & & & \\
Opportunity Recognition & 0.889 & 0.728 & 0.383 & 0.642 & 0.322 & 0.342 & 0.853 & & & \\
Proactiveness & 0.869 & 0.623 & 0.460 & 0.587 & 0.534 & 0.538 & 0.487 & 0.789 & & \\
RiskPropensity & 0.804 & 0.673 & 0.373 & 0.457 & 0.398 & 0.582 & 0.447 & 0.526 & 0.820 & \\
SelfEfficacy & 0.821 & 0.605 & 0.411 & 0.431 & 0.464 & 0.577 & 0.402 & 0.660 & 0.513 & 0.778 \\
\hline
\end{tabular}

Note: CR- Composite Reliability; AVE- Average Variance Extracted

\subsection{Structural Model Assessment}

The structural model displays the relationships (paths) between the constructs. Figure 1 represents the structural model results with the coefficients for each path that indicates the causal relations among the constructs in the model. The tests on the significance of the path and hypothesis in the path model were performed using the SmartPLS's bootstrap re-sampling technique. All the independent variables provided $42.2 \%$ variance explained in innovative behavior (H1 is supported) and thus contributed $41.3 \%$ of variance explained in opportunity recognition. Only creativity and proactiveness showed a significant relationship to both innovative behavior and opportunity recognition. Innovative behavior showed a significant relationship to opportunity recognition $(\beta=0.642, t=14.436$, $\mathrm{p}=0.000$ ). Therefore $\mathrm{H} 2$ is supported. Other generic skills disclose insignificant relationships to innovative behavior and opportunity recognition. Even though, collectively, it contributed moderately to both mediating and dependent variables. Details of indirect and direct effects are shown in Table 3.

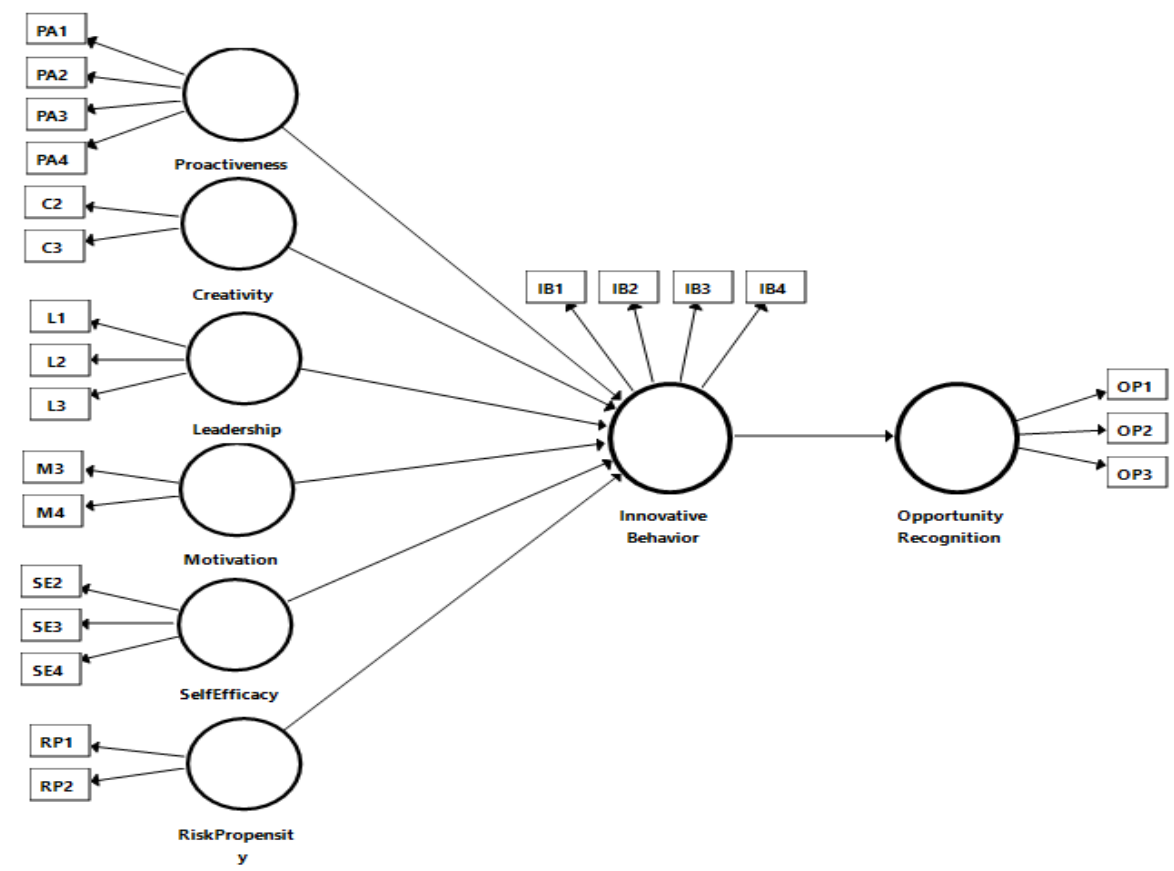

Figure 1. The Structural Model 
Table 3. Total effect

\begin{tabular}{lrrrr}
\hline & Beta & SD & T-value & P Values \\
\hline Creativity -> Innovative Behavior & 0.238 & 0.066 & 3.607 & 0.000 \\
Creativity -> Opportunity Recognition & 0.153 & 0.044 & 3.489 & 0.001 \\
Leadership -> Innovative Behavior & -0.013 & 0.069 & 0.193 & 0.847 \\
Leadership -> Opportunity Recognition & -0.009 & 0.045 & 0.192 & 0.848 \\
Motivation -> Innovative Behavior & 0.062 & 0.078 & 0.797 & 0.426 \\
Motivation -> Opportunity Recognition & 0.040 & 0.051 & 0.784 & 0.433 \\
Proactiveness -> Innovative Behavior & 0.397 & 0.084 & 4.744 & 0.000 \\
Proactiveness -> Opportunity Recognition & 0.255 & 0.059 & 4.334 & 0.000 \\
RiskPropensity -> Innovative Behavior & 0.146 & 0.087 & 1.665 & 0.096 \\
RiskPropensity -> Opportunity Recognition & 0.093 & 0.057 & 1.653 & 0.099 \\
SelfEfficacy -> Innovative Behavior & -0.033 & 0.075 & 0.449 & 0.654 \\
SelfEfficacy -> Opportunity Recognition & -0.021 & 0.048 & 0.444 & 0.658 \\
Innovative Behavior -> Opportunity Recognition & 0.642 & 0.044 & 14.436 & 0.000 \\
\hline
\end{tabular}

\section{Discussion}

This study attempts to investigate the generic skills that influence the innovative behavior of youth and opportunity recognition. Generic skills comprised of creativity, leadership, proactive, risk propensity, and self-efficacy. While Chell and Ahye (2009) and Afshari et a, found that all the generic skills showed positive and significant effects on innovative behavior, however, this study disclosed mixed results. Creativity and proactiveness showed positive and significant effects on innovative behavior. Interestingly, Kuckertz et al. (2017) found that creativity did not influence innovative behavior. The respondents were students who attended a technology entrepreneurship class. A part of their assignments is to propose a new product using their creative ideas. In order to do so, they have to embark on rigorous searches using various channels. They also had to choose and visited a company to explore the business opportunity and discussed their proposed innovative idea. This encourages them to be proactive and also taking a risk. However, as students were working in a group, the leadership was not emphasized. Also, self-efficacy is not directly relevant to this process. The findings also contrast to the previous study by Scott and Bruce (2017) that found that only leadership, individual problem-solving style, and workgroup relations affect innovative behavior directly and indirectly. Generally, the generic skills are developed through their lives and further enhanced and strengthen as they get involved in many students' activities. According to Chell and Athayde (2009), teaching style and extra-curricular activities encourage youth to develop skills for innovation. Finally, as more researches are focusing on innovative behavior, less attention was given to opportunity recognition, which is essential, especially for youth to set their future direction. This study has unveiled the determinants of innovative behavior using generic skills and its impact on opportunity recognition.

\section{Conclusions}

The objective of this study is to explore the impact of generic skills and innovative behavior towards opportunity recognition in entrepreneurship among youth. The findings have shown that most of the generic skills, such as leadership, motivation, self-efficacy, and risk propensity, had no impact on opportunity recognition. As more and more activities have been carried out to embed those skills, however, those skills remain ineffective and well-integrated in youth or students. Generic skills such as creativity, leadership, proactive, risk-taking, and self-efficacy should be given close attention, especially by stakeholders such as top management, lecturers, and staff. These determinants are essential, especially on leadership and self-efficacy that help them to embark great journey ahead. More efforts and better approaches need to be redesigned and implemented to encourage youth to have a strong self-efficacy, dare to take a risk as well as developing excellent leadership skills in innovative activities. Lecturers should reassess their roles to be more active towards students' innovative behavior and help students to recognize opportunities through various activities. It is a call to reassess our curriculum to ensure that generics skills are well delivered, and students or youth can see its importance. Youth are the future of the nation. Moving into industrial revolution 4.0, creativity and innovation have become critical elements for countries to create national 
wealth and prosperity in the long run. Therefore, youth play a significant role in these directions, thus focusing on developing their creativity and innovative behavior has become the central agenda. This study is not without limitations. Firstly, the findings cannot be generalized due to the small number of participants. Secondly, questions based on perception might not provide real insights. For future research, the survey on lecturers should be carried out to understand the level of leadership and proficiency in coaching students. Besides, other factors such as opportunity exploitation, ecosystem, peer support, and external influences worth to be explored.

\section{Acknowledgments}

The authors would like to express gratitude and appreciation to the Research Management Institute of Universiti Teknologi MARA and the Ministry of Education for supporting this research through LESTARI grant 600-IRMI 5/3/LESTARI (032/2018).

\section{References}

Afshari, M., Siraj, S., Ghani, M. A. F., \& Abdul Razak, A. Z. (2012). Enhancing Students' Creativity at Research Universities in Malaysia. Archives Des Sciences, 65(6), 166-172.

Antoncic, J. A., Antoncic, B., Gantar, M., Hisrich, R. D., Marks, L. J., Bachkirov, A. A., ... Coelho, A. (2018). Risk-Taking Propensity and Entrepreneurship: The Role of Power Distance. Journal of Enterprising Culture, 26(1), 1-26. https://doi.org/10.1142/S0218495818500012

Carmeli, A., Meitar, R., \& Weisberg, J. (2006). Self-leadership skills and innovative behavior at work. International Journal of Manpower, 27(1), 75-90.

Chell, E., \& Athayde, R. (2009). The identification and measurement of the innovative characteristics of young people. Research report: July 2009 National Endowment for Science, Technology and the Arts, Kingston University.

Crebert, G., Patrick, C-J., \& Cragnolini, V. ( 2004). Developing generic skills at university, during work placement and in employment: Graduates' perceptions. Higher Education Research and Development, 24(2). https://doi.org/10.1080/0729436042000206636

De Jong, J., \& Den Hartog, D. (2010). Measuring Innovative Work Behavior. Creativity and Innovation Management, 19. https://doi.org/10.1111/j.1467-8691.2010.00547.x

Devadason, E. S., Subramaniam, T., \& Daniel, E. G. S. (2010). Final year undergraduates' perceptions of the integration of soft skills in the formal curriculum: a survey of Malaysian public universities. Psychology. https://doi.org/10.1007/s12564-010-9090-4

Dyer, J. H., Gregersen, H. B., \& Christensen, C. (2008). Entrepreneur Behaviors, Opportunity Recognition, And The Origins Of Innovative Ventures. Journal of Strategic Entrepreneurship, 2, 317-338. https://doi.org/10.1002/sej.59

Fornell \& Larcker. (1981). Evaluating Structural Equation Models with Unobservable Variables and Measurement Error. Journal of Marketing Research, 48, 39-50.

Hair, J. F., Black, W. C., Babin, B. J., \& Anderson, R. E. (2010). Multivariate Data Analysis (7th ed.). Prentice-Hall, Upper Saddle River, New Jersey.

Heinonen, J., Hytti, U., \& Stenholm, P. (2011). The Role of Creativity in Opportunity Search and Business Idea Creation. Education and Training, 53, 659-672. https://doi.org/10.1108/00400911111185008

Hsiao, H. S., Chang, J. C., Tu, Y. L., \& Chen, S. C. (2010). The Impact of Self-efficacy on Innovative Work Behavior for Teachers. International Journal of Social Science and Humanity, 1(1), 31-36.

Kim, J. Y., Choi, D. S., Sung, C. S., \& Park, J. Y. (2018). The role of problem-solving ability on innovative behavior and opportunity recognition in university students. Journal of Open Innovation: Technology, Market, and Complexity, 4(4). https://doi.org/10.1186/s40852-018-0085-4

Kong, Y., \& Li, M. (2018). Proactive personality and innovative behavior: The mediating roles of job-related effect and work engagement. Social Behavior and Personality: An International Journal, 46, 431-446.

Kuckertz, A., Kollmann, T., Krell, P., \& Stöckmann, C. (2017). Understanding, differentiating and measuring opportunity recognition and opportunity exploitation. International Journal of Entrepreneurial Behavior \& Research, 23(1), 78-97. https://doi.org/10.1108/IJEBR-12-2015-0290

Li, M., Liu, Y., Liu, L., \& Wang, Z. (2017). Proactive Personality and Innovative Work Behavior: The Mediating 
Effects of Affective States and Creative Self-Efficacy in Teachers. Current Psychology, 36(4), 697-706.

Lovell, K. (2017). Millennial Entrepreneurs: Investing in Youth as the Future of Innovation and Economic Growth. Entrepreneur Asia Pacific. Retrieved from https://www.entrepreneur.com/article/296443

Ministry of Higher Education. (2015). Employability in Malaysia: Selected Works. Retrieved from http://mycc.my/document/files/PDF\%20Dokumen/Employability\%20in\%20Malaysia\%20Selected\%20Works.p df

Nab, J., Beugels, J., van Keulen, H., Oost, H. A., \& Pilot, A. (2008). Opportunity recognition in entrepreneurship education, design principles on fostering competent entrepreneurs in the science domain.

Ngah, R., \& Osman, C. A. (2017). Entrepreneurship Education and Entrepreneurial Learning on Students' Entrepreneurial Intention in Malaysia: Investigating the Role of Entrepreneurial Self-Efficacy. Journal of Computational and Theoretical Nanoscience, 23(8), 7529-7533. https://doi.org/10.1166/asl.2017.9515

Riaz, S., Xu, Y., \& Hussain, S. (2018). Understanding Employee Innovative Behavior and Thriving at Work: A Chinese Perspective. Administrative Science, 8(46), 1-14. https://doi.org/10.3390/admsci8030046

Sambasivan, M., Abdul, M., \& Yusop, Y. (2009). Impact of Personal Qualities and Management Skills of Entrepreneurs on Venture Performance in Malaysia: Opportunity Recognition Skills as a Mediating Factor. Technovation, 29(11), 798-805. https://doi.org/10.1016/j.technovation.2009.04.002

Scott, S. G., \& Bruce, R. A. (2017). Determinants of Innovative Behavior: A Path Model of Individual Innovation in the Workplace. Academy of Management Journal, 37(3). https://doi.org/10.5465/256701

Swaroop, P., \& Dixit, V. (2017, June). Creativity, Innovation, and Innovative Behaviour at Work: Clearing the Conceptual Confusion. International Journal of Engineering Technology, Management, and Applied Sciences, 5(6). Retrieved from www.ijetmas.com

Tey, N. P., Lai, S. L., \& Ismail, N. A. (2019). Population Situation Analysis Malaysia 2018. Population Studies Unit (PSU) Faculty of Economics and Administration University of Malaya.

United Nation Economic and Social Council (UNCTAD). (2019). The impact of rapid technological change on sustainable development. Retrieved from https://unctad.org/meetings/en/SessionalDocuments/ecn162019d2_en.pdf

Wasdani, K. P., \& Manimala, M. J. (2015). Opportunity Recognition Skill of Entrepreneurs and Its Association with Their Paths to Entrepreneurship and Types of Innovations: An Empirical Investigation of SME Firms. Kindai Management Review, 3, 25-35.

Wetzels, M., \& Odekerken, G. (2009). Using PLS Path Modeling for Assessing Hierarchical Construct Models: Guidelines and Empirical Illustration. Management Information Systems Quarterly - MISQ, 33. https://doi.org/10.2307/20650284

Yassin, S., Hasan, F., Amin, W., \& Amiruddin, N. (2008). Implementation of Generic Skills in the Curriculum. Edith Cowan University Research Online. Proceedings of the EDU-COM 2008 International Conference. Sustainability in Higher Education: Directions for Change, Edith Cowan University, Perth Western Australia, 19-21 November 2008.

Yuan, F., \& Marquardt, D. J. (2015). Innovative Behavior. Management. Oxford University Press, London. https://doi.org/10.1093/obo/9780199846740-0054 